NBER WORKING PAPER SERIES

\title{
VALUE-ADDED TO WHAT? HOW A CEILING IN THE TESTING INSTRUMENT INFLUENCES VALUE-ADDED ESTIMATION
}

\author{
Cory Koedel \\ Julian Betts \\ Working Paper 14778 \\ http://www.nber.org/papers/w14778 \\ NATIONAL BUREAU OF ECONOMIC RESEARCH \\ 1050 Massachusetts Avenue \\ Cambridge, MA 02138 \\ March 2009
}

The authors thank Andrew Zau and many administrators at San Diego Unified School District, in particular Karen Bachofer and Peter Bell, for helpful conversations and assistance with data issues. We also thank Yixiao Sun, Julie Cullen, Nora Gordon and Dale Ballou for their useful comments and suggestions, and the Spencer Foundation and the National Center for Performance Incentives for research support. The underlying project that provided the data for this study has been funded by a number of organizations including The William and Flora Hewlett Foundation, the Public Policy Institute of California, The Bill and Melinda Gates Foundation, the Atlantic Philanthropies and the Girard Foundation. None of these entities has funded the specific research described here, but we warmly acknowledge their contributions to the work needed to create the database underlying the research. The views expressed herein are those of the author(s) and do not necessarily reflect the views of the National Bureau of Economic Research.

NBER working papers are circulated for discussion and comment purposes. They have not been peerreviewed or been subject to the review by the NBER Board of Directors that accompanies official NBER publications.

(C) 2009 by Cory Koedel and Julian Betts. All rights reserved. Short sections of text, not to exceed two paragraphs, may be quoted without explicit permission provided that full credit, including $\odot$ notice, is given to the source. 
Value-Added to What? How a Ceiling in the Testing Instrument Influences Value-Added Estimation

Cory Koedel and Julian Betts

NBER Working Paper No. 14778

March 2009

JEL No. I2,I21,I22,J08,J33,J45

\begin{abstract}
Value-added measures of teacher quality may be sensitive to the quantitative properties of the student tests upon which they are based. This paper focuses on the sensitivity of value-added to test-score-ceiling effects. Test-score ceilings are increasingly common in testing instruments across the country as education policy continues to emphasize proficiency-based reform. Encouragingly, we show that over a wide range of test-score-ceiling severity, teachers' value-added estimates are only negligibly influenced by ceiling effects. However, as ceiling conditions approach those found in minimum-competency testing environments, value-added results are significantly altered. We suggest a simple statistical check for ceiling effects.
\end{abstract}

\author{
Cory Koedel \\ Dept. of Economics \\ University of Missouri \\ 118 Professional Building \\ Columbia, MO 65211 \\ koedelc@missouri.edu \\ Julian Betts \\ Department of Economics, 0508 \\ University of California, San Diego \\ 9500 Gilman Drive \\ La Jolla, CA 92093-0508 \\ and NBER \\ jbetts@ucsd.edu
}


Teacher performance pay is quickly gaining momentum in the United States. In fact, some districts, and even entire states, are already implementing performance-pay programs for teachers that involve sizeable public expenditures. For example, the Texas Governor's Educator Excellence Award Programs (GEEAP) allot a large fraction of their combined 330 million dollar annual budget to directly reward classroom teachers based on performance (Podgursky and Springer, 2007).

The aspect of teacher performance that has received the most attention from policymakers of late, and is perhaps the most contentious, is value-added to students' test scores. While the literature overwhelmingly indicates that there are important differences in teacher quality measured by value-added, there is little consensus on the best approach for estimating value-added. Furthermore, there is ample evidence that value-added measures of teacher quality are noisy, which creates some concern about the feasibility of using value-added for large-scale teacher evaluation. ${ }^{1}$ In addition to these unresolved issues, value-added estimates may be sensitive to the quantitative properties of the testing instruments upon which they are based.

This paper evaluates the sensitivity of value-added to a particularly relevant testinginstrument property - the severity of test-score-ceiling effects. We refer to the tendency for gains in a student's test score to be smaller if the student's initial score is toward the top end of the distribution, simply because the student has little room for improvement given the difficulty level of the test, as a "ceiling effect". Ceiling effects will be most pronounced in minimumcompetency or proficiency-based tests, which are being used increasingly across the United States. For example, 22 states nationwide use high school exit exams that are typically pitched at

\footnotetext{
${ }^{1}$ See, for example, Aaronson, Barrow and Sander (2007), Hanushek, Kain, O’Brien and Rivkin (2005), Koedel and Betts (2007) and Rockoff (2004). In addition, Rothstein (2008) shows that value-added estimates may be biased by student-teacher sorting.
} 
a middle-school or lower high-school level. ${ }^{2}$ Furthermore, because federal No Child Left Behind (NCLB) legislation focuses largely on proficiency, mainstream proficiency-based testing is also becoming increasingly common.

The increased focus on proficiency in education coincides with the growing interest from researchers and policymakers in value-added as a tool for measuring teacher performance. The impending collision of ceiling-affected testing instruments with value-added-based teacher evaluations motivates our analysis. Do ceiling effects influence value-added estimation? If so, how important are ceiling effects and how severe must they be to significantly alter value-added results?

We answer these questions using a testing instrument where there is no evidence of a test-score ceiling. Starting with our no-ceiling baseline, we simulate test-score ceilings that vary in severity and evaluate their effects on teacher value-added. Our findings are generally encouraging - over a wide range of test-score-ceiling severity we find that value-added estimates are roughly impervious to ceiling effects. However, ceiling conditions approaching the severity of those found in minimum-competency testing environments noticeably alter value-added results.

\section{Test-Score Ceilings: Introduction and Measurement}

Test-score ceilings structurally restrict students' test-score gains as test-score levels rise. Because a test-score ceiling directly influences the tool by which value-added is measured, it is intuitive that it will influence results. For example, consider a testing instrument where a large fraction of the student population is at or near the maximum possible score. Teachers teaching these students will have little opportunity to add value to test scores. Furthermore, they are

\footnotetext{
${ }^{2}$ The nationwide count applies to 2006 and was calculated based on information in Warren (2007).
} 
likely to use advanced curricula that focus at least partly on material that goes beyond the scope of the test, making their evaluations based on the test uninformative.

In practice it might be quite important whether a district uses a norm-referenced or a criterion-referenced test for the purpose of evaluating teaching effectiveness. A norm-referenced test is a standardized test that is meant to estimate where a student ranks against the test-score distribution of the reference group, typically the national student population. Such a test, if welldesigned, should exhibit few ceiling effects because it must include questions with a range of difficulty so that distinctions can be made among students throughout the test-score distribution. Such tests have been in use for many decades.

More recently, partly as a consequence of NCLB, many states are using testing systems designed to measure student understanding of the content standards set by the state's Department of Education. We speculate that these "criterion-referenced" tests are more likely to exhibit ceiling effects, particularly when a state exam is intended, either explicitly or implicitly, to serve as a "minimum-competency" test. For example, in Mississippi the state-level test appears to be targeted at a fairly low level. In 2006-07, 90 percent of fourth-grade students scored at or above the "proficient" level in reading on the state-level Mississippi Curriculum Test (MCT). However, just 19 percent of these students scored at or above the proficient level on the National Assessment of Education Progress (NAEP). ${ }^{3,4}$

One way to evaluate the impact of ceiling effects on teacher value-added would be to find a population of students that had been tested in several consecutive years using two testing

\footnotetext{
${ }^{3}$ From the US Department of Education, Mapping Mississippi's Educational Progress 2008.

${ }^{4}$ Cullen and Loeb (2004) illustrate another source of ceiling effects that is directly associated with NCLB reporting requirements that require states to document the percentage of students who are "proficient". Their Figure $12 \mathrm{c}$ provides a graphical representation of the mechanical relationship between underlying proficiency levels and growth in proficiency. Clearly, if value-added were estimated based on simple pass-fail measures of student achievement, as emphasized by NCLB, ceiling effects would be severe.
} 
systems - one that lacked a ceiling effect and another that suffered from a ceiling effect. However, it is likely that the different tests in such a scenario would also differ in terms of content, confounding the ceiling effect. A second approach is to use a test that can be demonstrated not to suffer from ceiling effects, and then to simulate test-score ceiling effects using that instrument. This creates a counterfactual of what would have happened had the test been right-censored. We adopt this approach by using Stanford 9 math test scores for fourth grade students in the San Diego Unified School District. The Stanford 9 is a nationally normreferenced test. For the population we study we find no evidence of a ceiling effect (see below). It thus provides a way of comparing measures of teacher value-added with and without a testscore ceiling.

The first step in our analysis is to provide a reliable measure of test-score ceiling severity. An intuitive approach would be to evaluate the strength of the negative relationship between testscore levels and subsequent test-score gains. However, this approach is problematic because a negative relationship will exist due to regression to the mean even in the absence of a test-score ceiling. Furthermore, in cases where a test-score ceiling does exist, there is no obvious way to dissect the negative relationship between test-score levels and test-score gains to isolate the ceiling effect. As an alternative, we propose that the distribution of students' test scores can be used to measure test-score-ceiling severity. Specifically, we can use the degree of negative skewness in the test-score distribution as originally suggested by Roberts (1978). We define skewness as the sample analog of $\frac{E(x-E(x))^{3}}{\left[E(x-E(x))^{2}\right]^{3 / 2}} \equiv \frac{\mu_{3}}{\sigma^{3}}$, where $\mu_{3}$ is the third moment about the mean and $\sigma$ is the standard deviation. Under the assumption that underlying student achievement in the population is symmetrically distributed, skewness provides an intuitive and 
straightforward measure of test-score ceiling severity. In Section VII, we provide suggestive (although not exhaustive) evidence that skewness is a robust measure of ceiling severity.

Figure 1 displays the frequency distributions of students' lagged (grade 3) and current (grade 4) math test scores from our data, gathered from San Diego Unified School District. As mentioned above, there is no evidence of a test-score ceiling. In fact, the test-score distributions from our sample are skewed mildly positively. The figure shows kernel-density plots of the distributions of actual scores contrasted with normally-distributed overlays. The skewness in the lagged and current-score distributions in our data are 0.25 and 0.17 , respectively. Notice that although both of these distributions are skewed slightly positively, they both closely mirror their normally distributed analogs.

In our test-score-ceiling simulations, what is the relevant range of skewness to consider? We answer this question using two large-scale, state-level tests: (1) the Texas Assessment of Academic Skills (TAAS) and (2) the Florida Comprehensive Assessment Test (FCAT). ${ }^{5}$ The TAAS was administered in Texas from 1991 to 2003 and prior to 1991 was known as the Texas Educational Assessment of Minimum Skills. The minimum-competency-based design of the TAAS makes it a useful test upon which to base our most severe test-score-ceiling simulations. The FCAT was first administered in 1998 in Florida and continues to serve as the state-level standardized test there.

We simulate test-score-ceiling conditions based on the skewness in the test-score distributions of the math portions of the TAAS and FCAT from 2002 and 2007, respectively. Figure 2 shows kernel-density plots of third and fourth-grade mathematics scores on the TAAS compared to normally-distributed overlays based on 2002 test scores (statewide). The skewness

\footnotetext{
${ }^{5}$ Statewide distributions of test scores for the TAAS were provided online by the Texas Education Agency (http://www.tea.state.tx.us). FCAT scores were provided by the Florida Department of Education.
} 
in these score distributions is large and negative, at -1.60 and -2.08 , respectively. Similarly, the top panel of Figure 3 shows kernel density plots of third and fourth-grade mathematics scores on the 2007 FCAT (statewide). The skewness in these score distributions is also negative but much milder, at -0.46 and -0.55 . Finally, the bottom panel of Figure 3 shows the distributions of scores for ninth and tenth-grade students on the FCAT in 2007 where the skewness in the test-score distributions becomes increasingly negative. The ninth and tenth-grade score distributions from the FCAT have skewness of -0.94 and -1.99 , respectively. ${ }^{6}$

Starting with our no-ceiling baseline, we create counterfactual testing environments where students' scores are impeded by test-score ceilings of varying severity. Our most severe ceiling simulation is designed to mimic the testing conditions from the fourth-grade TAAS. For simplicity, we simulate what we will refer to as "hard" test-score ceilings, where students" scores are restricted at a specific maximum score. An alternative would be to simulate "soft" test-score ceilings that restrict student performance throughout the test-score distribution. For example, students' scores might taper off as they approach a maximum score. Soft test-score ceilings appear to characterize more accurately the true distributions of test scores in Figures 2 and 3. However, there are literally an infinite number of possible soft-ceiling structures that could generate the observed skewness in the TAAS and FCAT distributions, making such an analysis infeasible. Instead, we focus on hard test-score ceilings and compare the results that we obtain from our simulations to a set of results generated using one possible soft-ceiling structure. This analysis is detailed in Section VII and suggests that similarly skewed test-score distributions

\footnotetext{
${ }^{6}$ Students in Florida must pass the math portion of the tenth-grade FCAT to receive a high-school diploma. It is possible that the exam is targeted at a lower level because of this. Also, students are allowed to take the test more than once. The distribution of tenth-grade FCAT scores reported in Figure 3 is for all tests taken in 2007 (provided by the Florida Department of Education), which will include retaken exams. The retaken exams could either positively or negatively skew the distribution.
} 
have similar implications for value-added results, regardless of whether a hard or soft ceiling generates the ceiling effect.

Finally, we distinguish two mechanisms by which test-score ceiling effects will influence value-added estimation. First, most straightforwardly, ceiling effects represent lost information about student learning. The more severe is the test-score ceiling, the greater the amount of lost information. Second, ceiling effects will result in model misspecification. A test-score ceiling is a data censor, and as such the typical value-added approach is improperly specified in the presence of a ceiling. In practice this is a non-trivial problem because the underlying datacensoring structure will be unknown. Furthermore, the censoring problem is even more complicated in the value-added framework than in the typical dependent-variable censoring problem because lagged test scores will also be censored. In the general value-added approach (where current test scores are regressed on lagged test scores), this means that there will be censoring of an independent variable in addition to the censoring of the dependent variable. Converting to gainscores does not circumvent the problem because censoring will be ill-defined censored gainscores will have zero or near zero gains, but non-censored scores can also have zero, near zero, or even negative gains.

The current state of the data-censoring literature in econometrics and statistics is such that there is no solution to the data-censoring problem in this context. Therefore, distortionary test-score ceiling effects can be thought of as the product of both of these problems - lost information and model misspecification. For this reason, our primary results are from standard value-added models estimated by least squares. In Section VIII, we further consider the datacensoring problem and provide some evidence on the extent to which model misspecification alone drives our ceiling-effect results. 


\section{Background}

Only a fraction of the recent studies measuring teacher value-added have considered the potential importance of test-score ceiling effects. Furthermore, none have explicitly evaluated the direct implications of ceiling effects for value-added results. Hanushek, Kain, O’Brien and Rivkin (2005) provide the most provocative documentation of ceiling effects in the recent valueadded literature. These authors estimate value-added using the TAAS where scale scores are such that a gain of zero implies "typical" progress. They divide the exam into ten equal testscore intervals and assign each student to one of ten bins based on his or her period-(t-1) testscore level. There is a strong negative relationship between students' period-(t-1) test-score levels and period-t gains, which is suggestive of a ceiling effect (although mean reversion could also explain the documented relationship). More importantly, approximately two-thirds of the students in their sample are assigned to a bin where the average test-score gain is negative. Where "typical" progress is purported to correspond to a gain of zero, and in the absence of a ceiling effect, mean reversion in both directions would suggest that approximately equal shares of students should experience positive and negative gains. That such a large fraction of students show negative gains suggests that ceiling effects are an important concern. Their analysis is one of only a few that carefully considers test-score-ceiling effects, although a direct analysis of ceiling effects is beyond the scope of their study.

Of the other recent test-score-based studies of teacher quality, there is little mention of ceiling effects. Koedel (2008) and Koedel and Betts (2007) acknowledge the potential for testscore ceiling effects and report information on the relationship between students' gains and lagged test-score levels. Aaronson, Barrow and Sander (2007) measure value-added using two tests that differ substantially in terms of the distributions of scores, which they thoroughly 
document, but they do not explicitly consider ceiling effects. Rockoff (2004), who estimates teacher effects outside of the value-added framework, reports that 3 to 6 percent of the students in his sample attain the maximum possible score but he does not go into further detail. Lockwood et al. (2007) show that teacher effects are quite sensitive to different testing instruments but they do not consider the extent to which ceiling effects might be driving their results. Nye, Konstantopoulos and Hedges (2005) do not discuss test-score-ceiling effects.

\section{Value-Added Models}

We estimate teacher value-added using three different student-achievement specifications. Each specification implies tradeoffs in estimation. We focus on the general value-added model where current test scores are regressed on lagged test scores. It is somewhat common in the literature to use a specific form of the value-added model, the gainscore model, where the coefficient on the lagged test score is forced to one and the lagged-score term is moved to the left side of the equation. Although we do not present results from gainscore models, our findings are nearly identical using the gainscore framework. Results from the gainscore analogs to the below specifications are available from the authors upon request.

The first model that we consider, and the simplest, is a basic value-added model that allows for the comparison of teacher effects across schools:

$$
Y_{i t}=\phi_{t}+Y_{i(t-1)} \phi_{1}+X_{i t} \phi_{2}+T_{i t} \theta+\varepsilon_{i t}
$$

In (1), $Y_{i t}$ is the test score for student $i$ in year $t, \phi_{t}$ is a year-specific intercept, $X_{i t}$ is a vector of fixed and time-varying student-specific characteristics (see Table 1) and $T_{i t}$ is a vector of teacher indicator variables where the entry for the teacher who teaches student $i$ in year $t$ is set to one. The coefficients of interest are in the $\mathrm{Jx} 1$ vector of teacher effects, $\theta$. 
We refer to equation (1) as the basic model. The most obvious omission from the model is school-level information, whether in the form of school fixed effects or time-varying controls. Researchers have generally incorporated this information because of concerns that students and teachers are sorting into schools non-randomly. This sorting, along with the direct effects of school-level inputs on student achievement (peers, for example), will generate omitted-variables bias in the value-added results for teachers in equation (1).

While the omitted-variables-bias concern is certainly relevant, any model that includes school-level information will not allow for a true comparison of teacher effectiveness across schools. For example, if school fixed effects are included in equation (1) then each teacher's comparison group will be restricted to the set of teachers who teach at the same school. Furthermore, even in the absence of school fixed effects, the inclusion of school-level controls will restrict teachers' comparison groups to some extent because teachers may sort themselves based on school-level characteristics. If this is the case, controls meant to capture school quality will also partly capture school-level teacher quality, limiting inference from across-school comparisons of teachers.

For most researchers, concerns about omitted-variables bias dominate concerns about shrinking teacher comparison groups. This leads to the second model that we consider, the within-schools model, which is more commonly estimated in the literature and includes timevarying school-level covariates and school fixed effects. ${ }^{7}$

$$
Y_{i t}=\beta_{t}+Y_{i(t-1)} \beta_{1}+X_{i t} \beta_{2}+S_{i t} \beta_{3}+T_{i t} \gamma+v_{i t}
$$

\footnotetext{
${ }^{7}$ Although teacher effectiveness cannot be compared across schools straightforwardly using value-added estimates from (2), this may be acceptable from a policy perspective. For example, policymakers may wish to identify the best and worst teachers on a school-by-school basis regardless of any teacher sorting across schools.
} 
In (2), $S_{i t}$ is a vector that includes school indicator variables and time-varying school-level information for the school attended by student $i$ in year $t$. The controls in the vector $S_{i t}$ are detailed in Table 1. The benefit of including school-level information is a reduction in omittedvariables bias, including sorting bias generated by students and teachers selecting into specific schools.

Finally, we incorporate student fixed effects into the student achievement specification. This approach is suggested by Harris and Sass (2006), Koedel (2008) and Koedel and Betts (2007):

$$
Y_{i t}=\alpha_{i}+\alpha_{t}+Y_{i(t-1)} \alpha_{1}+X_{i t} \alpha_{2}+S_{i t} \alpha_{3}+T_{i t} \delta+u_{i t}
$$

In going from equation (2) to equation (3) we add the student fixed effects, $\alpha_{i}$. The inclusion of the student fixed effects also limits the entries in the vector $X_{i t}$ to include only time-varying student characteristics. The benefit of the within-students approach is that teacher effects will not be biased by within-school student sorting across teachers based on time-invariant student characteristics (such as ability, parental involvement, etc.). However, again there are tradeoffs. Equation (3) further narrows teachers' comparison groups to those with whom they share students. Thus, identification comes from comparing test-score gains for individual students when they were in the third and fourth grades. In addition, the incorporation of the student fixed effects makes the model considerably noisier. ${ }^{8}$ Finally, the inclusion of the student fixed effects restricts the size of the student population that can be considered because a student record must contain at least three contiguous test scores, instead of just two, to be included in the analysis. ${ }^{9}$

\footnotetext{
${ }^{8}$ In fact, a test for the statistical significance of the student fixed effects in equation (3) fails to reject the null hypothesis of joint insignificance. However, the test is of low power given the large-N, small-T panel dataset structure (typical of most value-added analyses), limiting inference.

${ }^{9}$ Equation (3) also introduces a potential endogeneity concern if teacher assignments are correlated with the timevarying error-term component across years. See Rothstein (2008) and Koedel and Betts (2008).
} 
Despite these concerns, econometric theory suggests that student fixed effects will be an effective way to remove within-school sorting bias as long as students and teachers are sorting based on time-invariant characteristics. We estimate the within-students model by firstdifferencing equation (3) and instrumenting for students' lagged test-score gains with their second-lagged levels. This general approach was developed by Anderson and Hsiao (1981) and has been recently used by Harris and Sass (2006), Koedel (2008) and Koedel and Betts (2007) to estimate teacher value-added. ${ }^{10}$

Two key issues distinguish the within-students model from the other models that we consider. First, to completely first-difference equation (3) we must incorporate students' lagged teacher assignments, which will appear in the period-(t-1) version of equation (3). That is, we are comparing the effectiveness of students' current and previous-year teachers. Second, the requirement that each student record contain three contiguous test scores in the within-students model not only limits the sample size overall but also restricts the student population to lesstransient students. Because these students tend to be higher achievers (see, for example, Rumberger and Larson, 1998; Ingersoll, Scamman and Eckerling, 1989), a given test-score ceiling will have a stronger effect on the restricted student sample. This issue will be revisited when we present our results.

\section{IV.Data}

We evaluate ceiling effects using administrative data from fourth-grade students in San Diego (San Diego Unified School District) who started the fourth grade between 1998-1999 and 2001-2002. We chose the fourth grade because it is an elementary-level grade (so that each student is linked to just one teacher) and because our student-fixed-effects model requires at least

\footnotetext{
${ }^{10}$ Although all three of these studies use the same basic methodology, Harris and Sass (2006) estimate their model using GMM while Koedel (2008) and Koedel and Betts (2007) use 2SLS. We use 2SLS here.
} 
three contiguous test-score records per student (students are first tested in the second grade). The standardized test that we use to measure student achievement is the Stanford 9 mathematics test. The Stanford 9 is designed to be vertically scaled such that a one-point gain in student performance at any point in the schooling process is meant to correspond to the same amount of learning. As discussed in Section I, there is no evidence of a ceiling effect in the test-score data.

Students who have fourth grade test scores and lagged test scores are included in our analysis. In our student-fixed-effects models, we also require students to have second-lagged test scores. For each model, we estimate value-added for teachers who teach at least 20 students across the data panel and restrict our student sample to the set of students taught by these teachers. ${ }^{11}$ In the models without student fixed effects, we evaluate test-score records for 30,354 students taught by 596 teachers. Our sample size falls to 15,592 students taught by 389 teachers in the student-fixed-effects model. The large reduction in sample size is the result of (1) the requirement of three contiguous test-score records per student instead of just two, which in addition to removing more transient students also removes one year-cohort of students because we do not have test-score data prior to 1997-1998 (that is, students in the fourth grade in 19981999 can have lagged scores but not second-lagged scores) and (2) requiring the remaining students be assigned to one of the 389 fourth-grade teachers who teach at least 20 students with three test-score records or more. ${ }^{12}$ We include students who repeat the fourth grade because our objective is to inform policy and it is unlikely that grade repeaters would be excluded from teacher evaluations in practice (because of moral hazard concerns). In our original sample of 30,354 students with current and lagged test-score records, just 199 are grade repeaters.

\footnotetext{
${ }^{11}$ This restriction is imposed because of concerns about sampling variation (see Kane and Staiger, 2002). Our results are not sensitive to reasonable adjustments to the 20 -student threshold.

${ }^{12}$ Only students who repeated the $4^{\text {th }}$ grade in the latter two years of our panel could possibly have had more than three test-score records. There are 32 students with four test-score records in our dataset.
} 
The degree of student-teacher sorting will influence the magnitude of test-score-ceiling effects. At one extreme, random assignment of students to teachers will mitigate ceiling effects insofar as they determine teacher rankings regardless of which model from Section III is used (although ceiling effects may still lead to an understatement the importance of teacher quality overall, and increase the noise associated with value-added estimation). ${ }^{13}$ At the other, a testscore ceiling where there is strong student-teacher sorting should lead to a large shift in teacher rankings based on value-added. ${ }^{14}$

One benefit of our analysis is that we can use real student-teacher matches from a real school district, rather than attempting to simulate student-teacher sorting. This is important because there is no consensus in the literature as to how students and teachers are actually assigned to one another, making it impossible to artificially generate student-teacher matches. However, if parents, students, teachers and administrators in San Diego act similarly to parents, students, teachers and administrators in other similar school districts, our results will generalize. ${ }^{15}$

We document observable student-teacher sorting in our data by comparing the average realized within-teacher standard deviation of students' lagged test scores to analogous measures based on simulated student-teacher matches that are either randomly generated or perfectly sorted. This approach follows Aaronson, Barrow and Sander (2007). Table 2 details our results, which are presented as ratios of the standard deviation of interest to the total within-grade

\footnotetext{
${ }^{13}$ If within-teacher student samples are small enough, random assignment will not be sufficient to entirely mitigate ceiling effects on teacher rankings.

${ }^{14}$ In addition to differential student-teacher sorting across districts and schools, there will also be differential sorting across schooling levels. Ceilings will have larger distortionary effects in higher grade levels if student-teacher sorting is stronger.

${ }^{15}$ The San Diego Unified School District (SDUSD) is the eighth largest school district in the nation, with considerable student diversity. The one notable difference between SDUSD and some other districts is that there is a larger-than-average share of English learners at SDUSD. For basic demographic information about the population of students and teachers at SDUSD see Betts, Zau and Rice (2003).
} 
standard deviation of the test (calculated based on our student sample). Note that while there does appear to be some student sorting based on lagged test-score performance, this sorting is relatively mild.

\section{Test-Score-Ceiling Simulations and Basic Results}

Our ceiling simulations are based on the distribution of students' test scores in the fourth grade. For example, one of our simulations imposes a ceiling where the maximum score is set at the $95^{\text {th }}$ percentile of the fourth grade test-score distribution. Because the Stanford 9 is vertically scaled, this ceiling definition spills over to third grade scores. That is, if a student in the third grade scores above the $95^{\text {th }}$ percentile in the distribution of fourth-grade scores, her third-grade score is set at the maximum. Our approach generates negative skewness in the test-score distributions for each grade. The skewness will be more pronounced in the fourth grade relative to the third grade, and in the third grade relative to the second grade. After imposing each testscore ceiling on our data, we re-standardize students' test scores within grades to have a mean of zero and a variance of one. ${ }^{16,17}$

\footnotetext{
${ }^{16}$ An alternative approach would have been to separately set the ceilings in the $2^{\text {nd }}, 3^{\text {rd }}$ and $4^{\text {th }}$ grades such that each ceiling is imposed at the $95^{\text {th }}$ percentile of its respective distribution. However, this approach is inconsistent with the evidence from the TAAS and, more mildly, the FCAT, where later-grade test-score distributions are more skewed. We do, however, evaluate such a ceiling structure when we consider the importance of differences in skewness across grades. See Table 6.

${ }^{17}$ Mechanically, the standardization of scores for each grade has no effect on results from the basic and withinschools models. In the within-students model, using within-grade standardized scores reduces the distortionary impacts of the test-score ceilings, albeit mildly. This occurs because the first-differenced test scores in the withinstudents models are scaled by their respective standard deviations before differencing, and the standard devation of fourth-grade scores is smaller than the standard deviation of third-grade scores. This effectively upweights test scores for students in the current year relative to the lagged year. Because ceilings are defined by skewness in the test-score distribution, a larger share of students have above average test-scores as ceiling severity increases across years. In our analysis, the relative up-weighting of these scores generated by the standardization appears to partially offset the dampening effect of the test-score ceiling. For any test-score distortions characterized by increased skewness over time (positive or negative), standardization should be somewhat helpful, although we note that the standardization question is of little practical importance here. Results from models of scaled scores analogous to those from standardized-scores models in the within-students analysis are available from the authors upon request. These results suggest even stronger distortionary ceiling effects.
} 
We create each test-score ceiling by imposing a maximum possible score that we do not allow students' scores to exceed. We consider test-score ceilings where the maximum score ranges from the $97^{\text {th }}$ percentile to the $33^{\text {rd }}$ percentile of the original distribution of fourth-grade scores. This latter ceiling generates skewness in the current and lagged test-score distributions comparable to skewness from the third and fourth-grade TAAS exams in 2002, as well as the ninth and tenth-grade FCAT exams in $2007 .{ }^{18}$ For each ceiling simulation, we report the skewness of the generated test-score distributions.

Tables 3, 4 and 5, respectively, show results from the three value-added models discussed above: the basic, within-schools and within-students models. When the ceilings are imposed, these models are misspecified because the data are censored. Therefore, the results from the tables document the combined effects of lost information and model misspecification. Again, because of the complications associated with properly modeling the data censoring given a realworld test-score ceiling, these results offer the most pragmatic representation of the influence of ceiling effects. We separately consider the data-censoring problem in more detail in Section VIII.

Each column in the tables shows results from a different test-score ceiling. The ceilings are increasing in severity moving from left to right, and the first column in each table shows results from our no-ceiling baseline for comparison. The negative skewness measures reported in rows (2) and (3) of each table (and in row (4) in Table 5) indicate the degree of ceiling severity. The eighth column of the tables shows results from our most severely skewed simulation, which we refer to as the "minimum-competency-equivalent" ceiling. For each ceiling simulation we report three measures of interest in addition to the skewness measures: (1)

\footnotetext{
${ }^{18}$ The lagged-score distribution is less-skewed than the distribution of $3^{\text {rd }}$-grade scores on the TAAS and more skewed than the distribution of $9^{\text {th }}$-grade scores on the FCAT. We evaluate the extent to which differences in skewness across grades influence value-added estimation in Table 6 and find very mild effects.
} 
the correlation between teachers' ceiling-affected value-added estimates and estimates from the baseline model without ceiling effects, (2) the estimation-error share of the variance of the teacher effects and (3) the adjusted and unadjusted effect sizes, by which we mean the predicted change in student achievement, as a proportion of one standard deviation of test scores, resulting from a one-standard-deviation increase in teacher quality. The correlations between the ceilingaffected and baseline estimates provide a quick gauge of the distortionary impacts of the ceilings. Teacher effect sizes are commonly used in the literature to evaluate the importance of differences in teacher quality. The unadjusted effect size is just the square root of the raw variance in teacher effects, while the adjusted measure accounts for estimation error in the individual teacher-effect estimates. These estimates are reported as ratios of the standard deviation of the teacher-effect distribution to the standard deviation of the censored test-score distribution for each ceiling simulation. This metric has a straightforward interpretation. For example, the southwest-most entry in Table 3, if taken at face value, suggests that a one-standard-deviation improvement in teacher quality corresponds to a 0.24 -standard-deviation improvement in test scores. The estimation-error shares of the teacher-effect variances and the corresponding adjusted variance measures are estimated following Koedel (2008), who separates the variance of the estimated teacher effects into signal and noise components. ${ }^{19}$

The three tables show that teachers' value-added estimates are roughly impervious to test-score-ceiling effects over a wide-range of ceiling severity in each model. This can be seen by looking at the correlations between the teacher effects estimated using the actual test-score data and those estimated after the ceilings are imposed. Notice that even the ceiling that affects

\footnotetext{
${ }^{19}$ For the within-students model we also report the skewness in the second-lagged test-score distribution. In the between and within-schools models we cluster standard errors at the student level. Because only grade-repeaters have more than one record, the clustered standard errors are essentially typical robust standard errors. Our withinstudents model is estimated using robust standard errors.
} 
students' test scores starting at the $75^{\text {th }}$ percentile is largely inconsequential (skewness $\approx-0.64$ ), as evidenced by the fairly high correlation between teachers' baseline value-added estimates and their value-added estimates from this ceiling simulation. So, for example, policymakers should feel comfortable using FCAT scores from the third and fourth grades, where the skewness in the test-score distributions are around -0.5 , to measure teacher value-added at least insofar as ceiling effects are a concern. However, value-added results begin to respond to ceiling effects as the ceilings continue to increase in severity. For instance, when the ceiling begins at the $50^{\text {th }}$ percentile of the fourth-grade test-score distribution, the correlation between the teacher-effect estimates from the actual data and the data with the ceiling imposed ranges from about 0.85 for the basic and within-schools models to 0.80 for the within-students model. The correlations drop further when we impose the ceiling at the $33^{\text {rd }}$ percentile, with the lowest correlation being 0.72 in the within-students model. As ceiling conditions approach those found in minimumcompetency testing environments, value-added results are non-negligibly altered.

Two other observations from Tables 3, 4 and 5 are noteworthy. First, the estimationerror share of the variance of teacher effects increases as ceiling severity increases, which surely explains part of the pattern in correlations discussed above. Second, there is a negligible change in the adjusted variance of teacher quality regardless of ceiling severity, which may initially seem counterintuitive. However, note that the test-score ceilings are reducing the raw variance of test scores overall, and that the teacher-effect variance measures are scaled by this underlying variance. That is, although the standard deviation of the teacher-effect distribution is reduced when a ceiling is imposed, the standard deviation of the distribution of test scores is also reduced. In fact, our analysis likely understates test-score-ceiling effects on the measurable 
variance of teacher quality because it removes variability in test-scores more precisely than would be observed in a real-world ceiling. ${ }^{20}$

Thus far we have focused on the effect of the magnitude of skewness on value-added estimation. But differences in skewness across grades may also affect value-added results. We evaluate this possibility in Table 6 by simulating variations of our most severe test-score ceiling. In the first column of Table 6 for each model, we impose a ceiling at the $33^{\text {rd }}$ percentile of the test-score distribution for each grade level separately, rather than basing the ceiling on the fourth-grade distribution of scores as in the previous analysis. This generates more closely aligned skewness in the test-score distributions across grades. In columns (2) and (3), we simulate less severe ceilings in the lagged-score distributions - these ceilings approach the severity of the ceiling in the lagged-score distribution from our initial simulation at the $33^{\text {rd }}$ percentile of fourth-grade scores. Table 6 shows that regardless of changes in the difference-inskewness across grades, the effect of the test-score ceiling on value-added results is roughly constant. $^{21}$ This can be most easily seen by comparing the correlations between the ceilingaffected value-added estimates and those from the no-ceiling baseline in row (7) of Table 6.

Finally, note that the test-score ceilings induce more skewness in the test-score distributions from the within-students sample (Table 5) relative to the larger student sample used in the basic and within-schools models (Tables 3 and 4). As mentioned in Section III, this is because the restricted student sample used for the within-students model is disproportionately affected by the test-score ceiling (that is, the set of students who have three contiguous test

\footnotetext{
${ }^{20}$ Our simulations allow students to demonstrate that they are far above the cutoff, and then we restrict their scores ex post. This removes additional variability in test scores that would be found near the highest possible score in a real-world test-score ceiling. For example, we might observe a student scoring at the $80^{\text {th }}$ percentile of the actual distribution of test scores and restrict her score to the $50^{\text {th }}$ percentile such that she obtains the maximum possible score in our simulation. However, with a real-world ceiling where she would have to answer every question correctly to score at the maximum, she might bubble in a wrong answer by accident, read a question incorrectly, etc. This would add to the underlying variability in test scores, but of course would not be explained by teacher effects.

${ }^{21}$ That is, over the fairly wide range of differences in skewness that we consider.
} 
scores is higher achieving, on average, than the set of students who have just two test scores). Interestingly, the influence of each test-score ceiling on value-added is similar across the three models despite the fact that each ceiling is more strongly felt by students in the within-students model. It appears that the stronger skewness in the test-score distributions for the restricted student sample is roughly offset by the benefit of looking within students, where ceiling effects will be partially controlled for by the first-differencing procedure.

\section{Implications of Minimum-Competency Testing for Value-Added Analysis}

We further evaluate the sensitivity of teacher value-added to the imposition of our most severe test-score ceiling, designed to replicate minimum-competency testing conditions, using transition matrices to compare teacher rankings before and after the test-score-ceiling transformation. The transition matrices provide an alternative documentation of the correlations reported in the final columns of Tables 3,4 and 5.

To construct the transition matrices, we estimate each model before and after the ceiling is imposed. In each case, we keep the vector of estimated teacher effects and rank them from 1 to $\mathrm{J}, 1$ being the lowest and $\mathrm{J}$ being the highest. We divide teachers into quintiles based on their value-added rankings, where quintile-5 teachers are those with the highest value-added. The transition matrices compare the stability of these quintile assignments before and after the ceiling is imposed. This type of analysis is particularly relevant in the context of teacher accountability. For example, an accountability system might reward the top 20 percent of teachers and sanction the bottom 20 percent as measured by value-added. Our results are reported in Table 7 for each of the value-added specifications described in Section III.

The vertical dimension of the transition matrices represents teachers' quintile rankings without the ceiling and the horizontal dimension teachers' rankings after the ceiling is imposed. 
Each cell in Table 7 indicates the percentage of teachers who fall into a given quintile set, where a quintile set is defined by the pair of quintile-rankings for a given teacher with and without the ceiling (e.g., the set $(1,4)$ would indicate a quintile ranking of " 1 " in the no-ceiling case and a quintile ranking of " 4 " after the ceiling is imposed). If ceiling effects did not influence valueadded rankings, the diagonal entries in Table 7 would all equal 100 percent and the off-diagonal entries would all equal zero.

The transition matrices show that ceiling effects alone can significantly influence valueadded rankings. For example, across the three models, just 49 to 56 percent of the teachers who are identified as being in the top 20 percent of the value-added distribution based on students' actual test scores are also identified as being in this group once test scores are transformed. Furthermore, 14 to 17 percent of these teachers are pushed below the $60^{\text {th }}$ percentile of the distribution of teacher effects.

In an omitted analysis available upon request, we also consider whether certain types of teachers are helped or harmed in terms of their value-added rankings by minimum-competency testing. The mechanism through which we might expect an effect is student-teacher sorting within and across schools. For example, if teachers with master's degrees teach a disproportionate share of high-achieving students, their value-added rankings will be more adversely affected by test-score-ceiling effects. Not surprisingly, we find that more qualified teachers, teachers with higher salaries, and teachers who teach at more advantaged schools are harmed by test-score ceiling effects in value-added rankings (the latter result related to the socioeconomic advantage of students across schools, of course, is only applicable in the basic value-added model). 


\section{Robustness of the Negative Skewness Measure}

In this section we evaluate the robustness of the negative skewness measure by evaluating whether differentially constructed test-score ceilings that produce similar negative skewness have similar implications for value-added results. In particular, we construct a set of soft test-score ceilings that are designed to replicate the negative skewness in some of the hardceiling simulations and look to see if the soft-ceiling design has different implications for valueadded results. We stress that our analysis here is far from exhaustive - for any given level of negative skewness in a test-score distribution, there are literally an infinite number of soft testscore ceiling structures that could generate the skewness. We focus on just one possibility here, creating soft test-score ceilings using a spline such that for a student with uncensored test score $Y_{i}$ :

$\tilde{Y}_{i}=Y_{i}, Y_{i} \leq S_{1}$

$\tilde{Y}_{i}=S_{1}+X_{1}\left(Y_{i}-S_{1}\right), S_{1}<Y_{i} \leq S_{2}$

$\tilde{Y}_{i}=S_{1}+X_{1}\left(S_{2}-S_{1}\right)+X_{2}\left(Y_{i}-S_{2}\right), S_{2}<Y_{i} \leq S_{3}$

$\vdots$

$\tilde{Y}_{i}=S_{1}+X_{1}\left(S_{2}-S_{1}\right)+X_{2}\left(Y_{i}-S_{2}\right)+\ldots+X_{n}\left(Y_{i}-S_{n}\right), Y_{i}>S_{n-1}$

In (4), $\tilde{Y}_{i}$ is the transformed score for student $i, S_{n}>S_{n-1}>\ldots>S_{1}$ where the $S_{j}, j=1, \ldots, n$ represent the test-score levels at which the $n$ knots appear, and $1 \geq X_{1} \geq X_{2} \geq \ldots X_{n-1} \geq X_{n}$, meaning that the test-score ceiling is non-decreasing in severity as students' test scores rise. Specifically we define $S_{n}$ as the score at the $n^{\text {th }}$ decile of the fourth-grade test-score distribution for these simulations. For student $i$ whose score falls between $S_{2}$ and $S_{3}$, her transformed score can be written (where $Y_{i}$ is her observed test score): 
$\tilde{Y}_{i}=S_{1}+X_{1}\left(S_{2}-S_{1}\right)+X_{2}\left(Y_{i}-S_{2}\right)$

We generate three soft test-score ceilings using this basic structure. These ceilings are designed to produce skewnesss in the distributions of test scores comparable to those from our

hard-ceiling simulations imposed at the $75^{\text {th }}, 50^{\text {th }}$ and $33^{\text {rd }}$ percentiles. Table 8 displays the $X_{n}$ vectors for each of these three ceilings.

Table 9 displays the effects of the three soft ceilings on value-added estimates from each of the three models discussed in Section III. The results are comparable to those in columns (6), (7) and (8) in Tables 3,4 and 5. Although the effects of the soft ceilings are slightly more mild than those from their hard-ceiling counterparts, the results suggest that similarly skewed testscore distributions have similar implications for value-added estimation.

\section{The Model Misspecification Problem}

Finally, we explicitly consider the model-misspecification problem, which has partly driven our results thus far. A least-squares approach (and variants thereof), which is typically used in the value-added literature, will be misspecified when there is a test-score ceiling because the ceiling acts as a data censor. When ceiling effects are severe, the misspecification problem will be amplified.

In theory one could estimate a censored-data model, such as a tobit model, to correct this misspecification. However, as a practical matter, there are three complications that arise with respect to resolving the model-misspecification problem in the value-added context where a testscore ceiling is detected. First, the censor points in a real-world test-score ceiling will be unknown and, in fact, discontinuous censor points may not even exist. Evidence from Carson and Sun (2007) suggests that mis-identifying the censor points will produce substantially biased 
estimates of the model parameters, meaning that "guessing" at the censor points based on some observed distribution of scores is unlikely to resolve the problem. ${ }^{22}$

A second complication of data censoring in the value-added context is that both current and lagged scores are likely to be censored. In the general value-added model, this means that an independent variable will be censored in addition to the dependent variable. The gainscore framework does not solve this problem because the censoring in a gainscore model is ill-defined (censored gains will be zero or near zero, but non-censored gains can also be zero, near zero, or even negative). Although dependent-variable data censoring has received considerable attention in research, there is a much smaller literature that considers independent-variable data censoring. Austin and Brunner (2003) and Austin and Hoch (2004) provide MLE solutions to the independent-variable censoring problem with a known censor point, but their solutions are sensitive to an assumption about the joint distribution of the independent variables. Where possible, even these authors strongly recommend circumventing the censoring problem altogether by obtaining uncensored data, or if the sample size permits, restricting the analysis only to uncensored observations. ${ }^{23}$

A third complication in the context of teacher value-added is that as the data censoring gets more severe, more and more teachers teach fewer and fewer students whose scores are not censored. At extreme ceiling severities, some teachers do not teach any students whose scores

\footnotetext{
${ }^{22}$ There has been some work in the econometrics literature that looks at data censoring when the censor points are unknown, but this literature is inapplicable to the case of a test-score ceiling because a key assumption required to overcome the unknown censoring process is that the censoring is independent of the underlying value of the censored variable (see Chen, 2002; Gørgens and Horowitz, 1999). This assumption obviously does not apply when the dependent variable, the test score, is subject to a ceiling effect.

${ }^{23}$ Whereas thus far we have treated ceiling effects as a 'problem' for value-added estimation, an alternative view is that ceiling effects simply signify a shift in the objective function of administrators toward helping students whose scores are not impacted by the ceiling. In such cases, modeling student achievement only for students whose scores are below the ceiling, if such a ceiling can be reasonably identified, will be a viable option. However, if school administrators do not want to shift disproportionate weight to low-achieving students in teachers' value-added estimates, the ceiling 'problem' resurfaces.
} 
are not censored. Clearly, as a larger fraction of the student population's scores are censored, inference for more and more teacher effects becomes unreliable. Thus, where ceiling effects are mild and the misspecification issue has little bearing on the results, a model that appropriately treats the censored data could in principle be informative for most if not all of the teacher effects. However, as ceiling effects become increasingly severe, and therefore the data-censoring correction would be most useful, the estimates for more and more teachers become uninformative.

Overall, these three issues suggest that a statistical solution to the misspecification problem, although theoretically possible, is unlikely to be successful. If a severe test-score ceiling is detected, the most reasonable solution is to find a different testing instrument. The results from this analysis can be useful for determining whether a test-score ceiling is sufficiently severe such that an alternative test should be considered.

Despite these practical difficulties, as a thought experiment it may be of interest to identify the separate impacts of lost information and model misspecification on value-added results. In Table 10, we briefly evaluate this question at the level of school effects (for our baseline sample of fourth-grade students) using a basic tobit model. ${ }^{24}$ We focus on school effects to circumvent the problem that at the teacher level, some teachers teach only students with censored scores in the most severe ceiling simulations (where this analysis is most interesting). In all schools, there are at least some students below the cutoff in all of our simulations. In addition, we avoid the added complication of independent-variable data

\footnotetext{
${ }^{24}$ Unlike OLS, heteroskedasticity in the case of tobit implies inconsistency in the coefficient estimates, and there is substantial heteroskedasticity here. There is some argument in the literature as to how important this is as a practical matter (see, for example, Arabmazar and Schmidt, 1981; Brown and Moffit, 1983; Hurd, 1979), but in our case a tobit that directly models the heteroskedasticity in the data performs worse than a simple tobit. We can only speculate as to the cause in our context - one possibility is that in the heteroskedastic tobit, the large number of (sometimes imprecisely) estimated heteroskedasticity parameters upon which the parameter-estimates of interest are based may be problematic.
} 
censoring by only censoring current scores (in practice this has a negligible effect on results). Although our partial-censoring approach to estimating school effects is not directly comparable to the preceding analysis, it provides a straightforward setting in which to evaluate separately the information-loss and model-misspecification components of test-score-ceiling effects. For brevity, Table 10 reports only the correlations of school effects across models. In our schooleffect models we control for the student-level covariates documented in Table 1 (that is, we replace the vector of teacher indicator variables with a vector of school indicator variables in the basic value-added model).

Table 10 shows that the tobit specification improves model performance, and substantially so. For example, even in the minimum-competency-equivalent simulation where a significant amount of test-score information is lost, modeling the censored data dramatically improves performance. Although the correlation between the baseline school effects and the ceiling-influenced school effects is still far from one in the most severe ceiling simulation, it is

much improved (going from 0.78 to 0.90 ). This exercise suggests that the modelmisspecification problem is an important contributor to the ceiling-effect distortions documented in our primary analysis.

\section{Concluding Remarks}

In the current climate of proficiency-based educational reform, test-score ceilings are likely to be increasingly common. We evaluate the extent to which ceiling effects influence the estimation of teacher value-added. There are two mechanisms by which ceiling effects distort value-added results. First, most straightforwardly, a test-score ceiling represents lost information about student learning. Second, a ceiling generally results in model misspecification. Although 
in theory this latter issue can be resolved by properly modeling the censored data, in practice a statistical solution to the data censoring problem is unlikely to be feasible.

Our analysis properly treats the test-score-ceiling problem as a combination of these two distortionary influences. Overall, our findings are generally encouraging - given a wide range of test-score ceiling conditions, some of which might be casually identified as severe, valueadded estimates are only negligibly affected. However, researchers and policymakers should be concerned when working in minimum-competency or proficiency-based testing environments. We show that ceiling conditions in such environments can significantly alter value-added assessments for individual teachers. 


\section{Figures}

Figure 1. Frequency Distributions of Lagged and Current Math Test Scores from our Data Contrasted with NormalDistribution Overlays
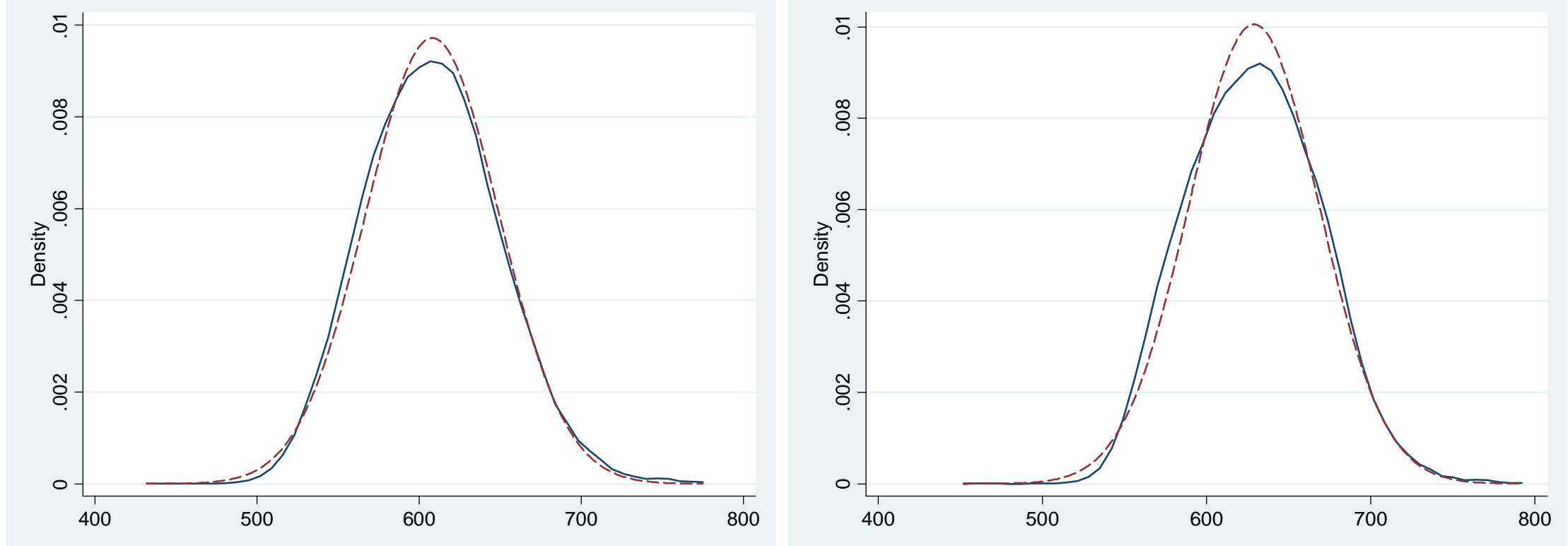

LEFT: Kernel-density plot of lagged test score distribution - skewness $\approx 0.25$

RIGHT: Kernel-density plot of current test score distribution - skewness $\approx 0.17$

In each graph the solid line represents the distribution of actual scores and the dotted line the normal-distribution overlay. Estimates are calculated using the Epanechnikov kernel with a bandwidth equal to 2.5 percent of the range of test scores. 
Figure 2. Frequency Distributions of Third and Fourth-Grade Math Scores from the TAAS in 2002 Contrasted With NormalDistribution Overlays
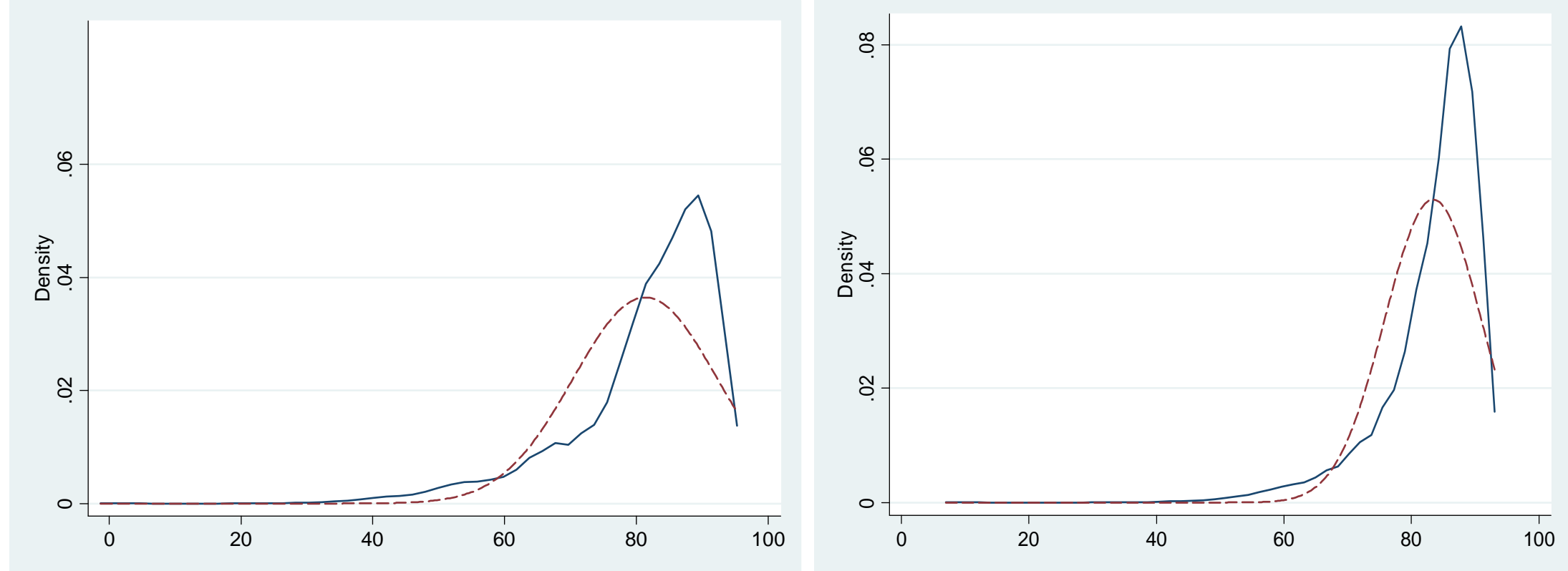

LEFT: Kernel-density plot of third-grade test score distribution - skewness $\approx-1.60$

RIGHT: Kernel-density plot of fourth-grade test score distribution - skewness $\approx-2.08$

In each graph the solid line represents the distribution of actual scores and the dotted line the normal-distribution overlay. Estimates are calculated using the Epanechnikov kernel with a bandwidth equal to 2.5 percent of the range of test scores. 
Figure 3. Frequency Distributions of Third, Fourth, Ninth and Tenth-Grade Math Scores from the FCAT in 2007 Contrasted With Normal-Distribution Overlays
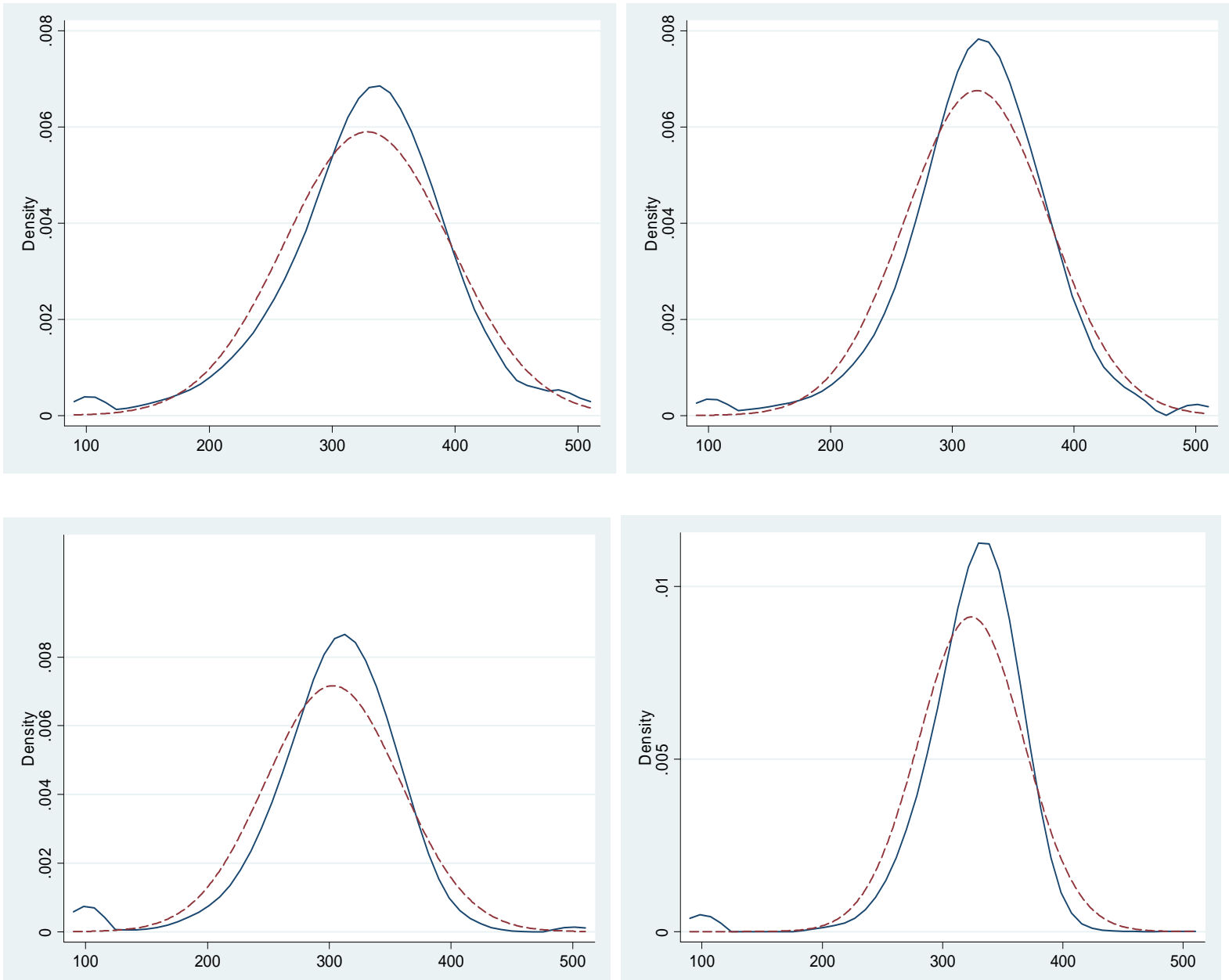

UPPER LEFT: Kernel-density plot of third-grade test score distribution - skewness $\approx-0.46$

UPPER RIGHT: Kernel-density plot of fourth-grade test score distribution - skewness $\approx-0.55$

LOWER LEFT: Kernel-density plot of ninth-grade test score distribution - skewness $\approx-0.94$

LOWER RIGHT: Kernel-density plot of tenth-grade test score distribution - skewness $\approx-1.99$

In each graph the solid line represents the distribution of actual scores and the dotted line the normal-distribution overlay. Estimates are calculated using the Epanechnikov kernel with a bandwidth equal to 2.5 percent of the range of test scores. 


\title{
Tables
}

Table 1. Controls from Value-Added Models

$\underline{\text { Student-Level Controls }\left(X_{i t}\right)}$

English-Learner (EL) Status

Change from EL to English-Proficient

Expected and Unexpected School Changer

Parental Education

Race

Gender

Designated as Advanced Student

Percentage of School Year Absent* $\underline{\text { School (and Classroom)-Level Controls }\left(S_{i t}\right)}$

School Fixed Effects

Classroom-level Peer Performance in Year (t-1)

Class Size

Percentage of Student Body:

by Race

by English Learner Status

by Free/Reduced-Price Lunch Status

by School-Changer Status

*The share of days missed by students is sometimes considered endogenous. Fourth-grade students, however, are not likely to have much influence over their attendance decisions.

Table 2. Average Within-Teacher Standard Deviations of Students' Period (t-1) Test Scores

\begin{tabular}{ccccc} 
Actual & \multicolumn{2}{c}{ Within Schools } & \multicolumn{2}{c}{ Across District } \\
Random & Perfect & Random & Perfect \\
Assignment & Sorting & Assignment & Sorting
\end{tabular}

\begin{abstract}
Standard Deviations of Lagged Scores $\begin{array}{lll}0.81 & 0.90 & 0.32\end{array}$

0.99

$<0.01$

Note: The numbers above report the average standard deviation of test scores within the classroom, for various scenarios, each divided by the overall standard deviation of test scores district-wide. In the "Perfect Sorting" columns students are sorted by period (t-1) test-score levels in math, first within school and in the final column across the district. For the randomized assignments, students are assigned to teachers based on randomly generated numbers from a uniform distribution. In the second column of numbers, students are not re-assigned across schools; in the fourth column, students are re-assigned across schools. The random assignments are repeated 25 times and estimates are averaged across all random assignments and all teachers. The estimates from the simulated random assignments are very stable across simulations.
\end{abstract}




\begin{tabular}{|c|c|c|c|c|c|c|c|c|}
\hline & $(1)^{*}$ & (2) & (3) & (4) & (5) & (6) & (7) & (8) \\
\hline $\begin{array}{l}\text { Percentile of Fourth-Grade Test-Score } \\
\text { Distribution Where Ceiling is Set }\end{array}$ & 99.96 & 97 & 95 & 90 & 85 & 75 & 50 & 33 \\
\hline $\begin{array}{l}\text { Skewness of Period-t Score } \\
\text { Distribution }\end{array}$ & 0.17 & -0.02 & -0.07 & -0.25 & -0.37 & -0.64 & -1.31 & -2.00 \\
\hline $\begin{array}{l}\text { Skewness of Period-(t-1) Score } \\
\text { Distribution }\end{array}$ & 0.25 & 0.11 & 0.07 & -0.05 & -0.13 & -0.32 & -0.83 & -1.32 \\
\hline $\begin{array}{l}\text { Correlation Between Ceiling-Restricted } \\
\text { Value-Added Estimates and Baseline }\end{array}$ & - & 0.99 & 0.99 & 0.98 & 0.97 & 0.94 & 0.85 & 0.77 \\
\hline $\begin{array}{l}\text { Estimation-error share of variance of } \\
\text { teacher fixed effects }\end{array}$ & 0.11 & 0.11 & 0.11 & 0.11 & 0.12 & 0.13 & 0.17 & 0.24 \\
\hline $\begin{array}{l}\text { Unadjusted Effect Size of Teacher } \\
\text { Quality }\end{array}$ & 0.26 & 0.25 & 0.25 & 0.25 & 0.25 & 0.25 & 0.26 & 0.26 \\
\hline $\begin{array}{l}\text { Adjusted Effect Size of Teacher } \\
\text { Quality }\end{array}$ & 0.24 & 0.24 & 0.24 & 0.24 & 0.24 & 0.24 & 0.23 & 0.23 \\
\hline
\end{tabular}

* Column (1) shows results from the no-ceiling baseline. Of course, a ceiling is not "set" here - 0.04 percent of the student population attains the maximum possible score. The last two rows show the unadjusted and adjusted estimates of the number of standard deviations by which student achievement is predicted to change after a one standard deviation increase in teacher quality. 
Table 4. Test-Score-Ceiling Effects on Value-Added Results: Within-Schools Specification

\begin{tabular}{|c|c|c|c|c|c|c|c|c|}
\hline & $(1)^{*}$ & (2) & (3) & (4) & (5) & (6) & (7) & (8) \\
\hline $\begin{array}{l}\text { Percentile of Fourth-Grade Test-Score } \\
\text { Distribution Where Ceiling is Set }\end{array}$ & 99.96 & 97 & 95 & 90 & 85 & 75 & 50 & 33 \\
\hline $\begin{array}{l}\text { Skewness of Period-t Score } \\
\text { Distribution }\end{array}$ & 0.17 & -0.02 & -0.07 & -0.25 & -0.37 & -0.64 & -1.31 & -2.00 \\
\hline $\begin{array}{l}\text { Skewness of Period-(t-1) Score } \\
\text { Distribution }\end{array}$ & 0.25 & 0.11 & 0.07 & -0.05 & -0.13 & -0.32 & -0.83 & -1.32 \\
\hline $\begin{array}{l}\text { Correlation Between Ceiling-Restricted } \\
\text { Value-Added Estimates and Baseline }\end{array}$ & - & 0.99 & 0.99 & 0.97 & 0.96 & 0.93 & 0.84 & 0.73 \\
\hline $\begin{array}{l}\text { Estimation-error share of variance of } \\
\text { teacher fixed effects }\end{array}$ & 0.24 & 0.24 & 0.24 & 0.25 & 0.26 & 0.28 & 0.35 & 0.44 \\
\hline $\begin{array}{l}\text { Unadjusted Effect Size of Teacher } \\
\text { Quality }\end{array}$ & 0.28 & 0.27 & 0.27 & 0.27 & 0.27 & 0.27 & 0.29 & 0.30 \\
\hline $\begin{array}{l}\text { Adjusted Effect Size of Teacher } \\
\text { Quality }\end{array}$ & 0.24 & 0.24 & 0.24 & 0.24 & 0.23 & 0.23 & 0.23 & 0.22 \\
\hline
\end{tabular}




\begin{tabular}{|c|c|c|c|c|c|c|c|c|}
\hline & $(1)^{*}$ & (2) & (3) & (4) & (5) & (6) & (7) & (8) \\
\hline $\begin{array}{l}\text { Percentile of Fourth-Grade Test-Score } \\
\text { Distribution Where Ceiling is Set }\end{array}$ & 99.96 & 97 & 95 & 90 & 85 & 75 & 50 & 33 \\
\hline $\begin{array}{l}\text { Skewness of Period-t Score } \\
\text { Distribution }\end{array}$ & 0.17 & -0.10 & -0.16 & -0.36 & -0.49 & -0.79 & -1.58 & -2.39 \\
\hline $\begin{array}{l}\text { Skewness of Period-(t-1) Score } \\
\text { Distribution }\end{array}$ & 0.25 & 0.07 & 0.02 & -0.13 & -0.22 & -0.43 & -1.03 & -1.62 \\
\hline $\begin{array}{l}\text { Skewness of Period-(t-2) Score } \\
\text { Distribution }\end{array}$ & 0.15 & 0.12 & 0.11 & 0.07 & 0.04 & -0.04 & -0.32 & -0.63 \\
\hline $\begin{array}{l}\text { Correlation Between Ceiling-Restricted } \\
\text { Value-Added Estimates and Baseline }\end{array}$ & - & 0.99 & 0.99 & 0.97 & 0.96 & 0.92 & 0.80 & 0.72 \\
\hline $\begin{array}{l}\text { Estimation-error share of variance of } \\
\text { teacher fixed effects }\end{array}$ & 0.33 & 0.33 & 0.33 & 0.34 & 0.34 & 0.37 & 0.45 & 0.51 \\
\hline $\begin{array}{l}\text { Unadjusted Effect Size of Teacher } \\
\text { Quality }\end{array}$ & 0.29 & 0.29 & 0.29 & 0.29 & 0.29 & 0.30 & 0.32 & 0.35 \\
\hline $\begin{array}{l}\text { Adjusted Effect Size of Teacher } \\
\text { Quality }\end{array}$ & 0.23 & 0.24 & 0.24 & 0.24 & 0.24 & 0.24 & 0.24 & 0.25 \\
\hline
\end{tabular}

* Column (1) shows results from the no-ceiling baseline. Of course, a ceiling is not "set" here -0.04 percent of the student population attains the maximum possible score. The last two rows show the unadjusted and adjusted estimates of the number of standard deviations by which student achievement is predicted to change after a one standard deviation increase in teacher quality. 
Table 6. Effects of Differences in Skewness across Grades on Value-Added Estimates from Each Model, Based on our Most Severe Ceiling Simulation

\begin{tabular}{|c|c|c|c|c|c|c|c|c|c|c|c|c|}
\hline & \multicolumn{4}{|c|}{ Basic Model } & \multicolumn{4}{|c|}{ Within-Schools Model } & \multicolumn{4}{|c|}{ Within-Students Model ${ }^{* *}$} \\
\hline & (1) & (2) & (3) & $(4)^{*}$ & (1) & (2) & (3) & $(4)^{*}$ & (1) & (2) & (3) & $(4)^{*}$ \\
\hline $\begin{array}{l}\text { Share of Fourth-Grade Students at Highest } \\
\text { Score }(\%)\end{array}$ & 67 & 67 & 67 & 67 & 67 & 67 & 67 & 67 & 67 & 67 & 67 & 67 \\
\hline $\begin{array}{l}\text { Share of Lagged Scores at Highest Score } \\
(\%)\end{array}$ & 67 & 60 & 50 & 47 & 67 & 60 & 50 & 47 & 67 & 60 & 50 & 47 \\
\hline $\begin{array}{l}\text { Share of Second-Lagged Scores at Highest } \\
\text { Score }(\%)\end{array}$ & $N / A$ & $N / A$ & $N / A$ & $N / A$ & $N / A$ & $N / A$ & $N / A$ & $N / A$ & 67 & 60 & 50 & 25 \\
\hline Skewness of Period-t Score Distribution & -2.00 & -2.00 & -2.00 & -2.00 & -2.00 & -2.00 & -2.00 & -2.00 & -2.39 & -2.39 & -2.39 & -2.39 \\
\hline $\begin{array}{l}\text { Skewness of Period-(t-1) Score } \\
\text { Distribution }\end{array}$ & -2.21 & -1.84 & -1.45 & -1.32 & -2.21 & -1.84 & -1.45 & -1.32 & -2.77 & -2.27 & -1.78 & -1.62 \\
\hline $\begin{array}{l}\text { Skewness of Period-(t-2) Score } \\
\text { Distribution }\end{array}$ & $N / A$ & $N / A$ & $N / A$ & $N / A$ & $N / A$ & $N / A$ & $N / A$ & $N / A$ & -2.17 & -1.79 & -1.48 & -0.63 \\
\hline $\begin{array}{l}\text { Correlation Between Ceiling-Restricted } \\
\text { Value-Added Estimates and No-Ceiling } \\
\text { Baseline }\end{array}$ & 0.79 & 0.79 & 0.78 & 0.77 & 0.73 & 0.73 & 0.73 & 0.73 & 0.72 & 0.69 & 0.70 & 0.72 \\
\hline $\begin{array}{l}\text { Estimation-error share of variance of } \\
\text { teacher fixed effects }\end{array}$ & 0.19 & 0.21 & 0.23 & 0.24 & 0.45 & 0.44 & 0.44 & 0.44 & 0.54 & 0.51 & 0.48 & 0.51 \\
\hline Unadjusted Effect Size of Teacher Quality & 0.26 & 0.26 & 0.26 & 0.26 & 0.30 & 0.30 & 0.30 & 0.30 & 0.36 & 0.36 & 0.36 & 0.35 \\
\hline Adjusted Effect Size of Teacher Quality & 0.24 & 0.23 & 0.23 & 0.23 & 0.22 & 0.22 & 0.22 & 0.22 & 0.24 & 0.25 & 0.26 & 0.25 \\
\hline $\begin{array}{l}* \text { The fourth column for the basic } \\
\text { comparison. That is, } 47 \text { percent } \\
* * \text { In the within-students panel, } t \\
\text { as directly comparable as possibl } \\
\text { within-students sample will score } \\
\text { are based on the restricted within- } \\
\text { within-students panel relative to } t \\
* * * \text { The last two rows show the } \\
\text { after a one standard deviation inc }\end{array}$ & $\begin{array}{l}\text { within-s } \\
\text { third gr } \\
\text { e ceiling } \\
\text { across } n \\
\text { t the ma } \\
\text { tudents } \\
\text { lagged } \\
\text { ladjuste } \\
\text { ease in } \mathrm{t}\end{array}$ & $\begin{array}{l}\text { lools, a1 } \\
\text { le stude } \\
\text { in the f } \\
\text { dels (i. } \\
\text { imum ir } \\
\text { mple. } \\
\text { core dis } \\
\text { and adju }\end{array}$ & $\begin{array}{l}\text { within- } \\
\text { attain } t \\
\text { th-grad } \\
\text { to replic } \\
\text { ach grac } \\
\text { s cause } \\
\text { bution. } \\
\text { ed estim }\end{array}$ & $\begin{array}{l}\text { dents } n \\
\text { score } \\
\text { nd lagg } \\
\text { as clo } \\
\text { evel ( } \\
\text { ightly } \\
\text { es of th }\end{array}$ & $\begin{array}{l}\text { ows th } \\
\text { percer } \\
\text { distrib } \\
\text { ssible } \\
\text { n III fo } \\
\text { ness in } \\
\text { of star }\end{array}$ & $\begin{array}{l}\text { sults fro } \\
\text { of the } \\
\text { ons are } \\
\text { effect } \\
\text { iscussio } \\
\text { period } \\
\text { rd devia }\end{array}$ & $\begin{array}{l}\text { the eig } \\
\text { arth-gra } \\
\text { igned b } \\
\text { true ce } \\
\text { Only } \\
\text {-2) distt } \\
\text { ns by }\end{array}$ & $\begin{array}{l}\text { colum } \\
\text { test-sc } \\
\text { ed on } t \\
\text { ng). N } \\
\text { ceiling } \\
\text { ution o } \\
\text { ch stud }\end{array}$ & $\begin{array}{l}\text { es } 3,4 \\
\text { pution. } \\
\text { dent sa } \\
\text { higher } \\
\text { econd- } \\
\text { colum } \\
\text { vemen }\end{array}$ & $\begin{array}{l}\text { 5, rest } \\
\text { le to } \mathrm{m} \\
\text { tre of th } \\
\text { (1), (2) } \\
\text { predict }\end{array}$ & $\begin{array}{l}\text { tively, } \\
\text { the ce } \\
\text { estricte } \\
\text { distribu } \\
\text { d (3) o } \\
\text { to chan }\end{array}$ & \\
\hline
\end{tabular}


Table 7. Transition Matrices Documenting the Stability of Teachers' Value-Added Rankings, by Quintile, Before and After the Minimum-Competency-Equivalent Ceiling is Imposed.

\section{Basic Model}

Ceiling-Affected Quintile Assignments

\begin{tabular}{ccccccc} 
& & 1 & 2 & 3 & 4 & 5 (best) \\
$\frac{\text { Baseline }}{\text { Quintile }}$ & 1 & 76 & 17 & 6 & 1 & 0 \\
$\underline{\text { Assignments }}$ & 2 & 22 & 43 & 25 & 10 & 0 \\
& 3 & 2 & 33 & 34 & 23 & 8 \\
& 4 & 0 & 7 & 20 & 36 & 38 \\
& 5 (best) & 0 & 2 & 14 & 30 & 54 \\
\hline
\end{tabular}

Notes: Cells report percentage of teachers in each quintile set.

Within-Schools Model

Ceiling-Affected Quintile Assignments

\begin{tabular}{ccccccc} 
& & 1 & 2 & 3 & 4 & 5 (best) \\
$\frac{\text { Baseline }}{\text { Quintile }}$ & 1 & $\mathbf{7 1}$ & 17 & 8 & 3 & 0 \\
Assignments & 2 & 24 & 39 & 24 & 11 & 3 \\
& 3 & 4 & 29 & 33 & 21 & 13 \\
& 4 & 1 & 13 & 19 & 39 & 28 \\
& 5 (best) & 0 & 2 & 16 & 26 & 56 \\
\hline
\end{tabular}

Notes: Cells report percentage of teachers in each quintile set.

Within-Students Model

Ceiling-Affected Quintile Assignments

\begin{tabular}{ccccccc} 
& & 1 & 2 & 3 & 4 & 5 (best) \\
$\frac{\text { Baseline }}{\text { Quintile }}$ & 1 & $\mathbf{5 8}$ & 24 & 13 & 4 & 1 \\
$\frac{\text { Assignments }}{3}$ & 2 & 35 & 35 & 23 & 6 & 1 \\
& 3 & 5 & 21 & 31 & 28 & 15 \\
& 4 & 3 & 12 & 17 & 37 & 32 \\
& 5 (best) & 0 & 9 & 17 & 25 & $\mathbf{4 9}$ \\
\hline
\end{tabular}

Notes: Cells report percentage of teachers in each quintile set. 
Table 8. Soft-Ceiling Simulations Designed to Mimic Hard Ceilings at the $75^{\text {th }}, 50^{\text {th }}$ and $33^{\text {rd }}$ Percentiles of the Distribution of Fourth-Grade Test Scores.

\section{$\underline{\text { Soft-Ceiling } 1}$}

Description:

Mimics the hard ceiling set at the $75^{\text {th }}$ percentile of the fourthgrade test-score distribution

\section{$\underline{\text { Soft-Ceiling } 2}$}

Mimics the hard ceiling set at the $50^{\text {th }}$ percentile of the fourthgrade test-score distribution

\section{$\underline{\text { Soft-Ceiling } 3}$}

Mimics the hard ceiling set at the $33^{\text {rd }}$ percentile of the fourthgrade test-score distribution

\begin{tabular}{cccc}
$X_{1}:$ & 1 & 1 & 1 \\
$X_{2}:$ & 1 & 1 & 0.60 \\
$X_{3}:$ & 1 & 0.90 & 0.40 \\
$X_{4}:$ & 1 & 0.70 & 0.20 \\
$X_{5}:$ & 0.90 & 0.30 & 0.10 \\
$X_{6}:$ & 0.70 & 0.10 & 0 \\
$X_{7}:$ & 0.50 & 0.10 & 0 \\
$X_{8}:$ & 0.30 & 0 & 0 \\
$X_{9}:$ & 0.10 & 0 & 0 \\
\hline
\end{tabular}


Table 9. Soft Ceiling Results.

Basic Model

Soft Ceiling Number

(from Table B.1)

Comparable to hard ceiling

imposed at

Share of Fourth-Grade Students at

Highest Score (\%)

Skewness of Period-t Score

Distribution

Skewness of Period-(t-1) Score

Distribution

Skewness of Period-(t-2) Score

Distribution

Correlation Between Ceiling-

Restricted Value-Added Estimates and Baseline

Estimation-error share of variance of teacher fixed effects

Unadjusted Effect Size of Teacher

Quality

Adjusted Effect Size of Teacher

Quality $\underline{\text { Within-Schools Model }}$

$\underline{\text { Within-Students Model }}$
(1)
(2)

(3)

(1)

(2)

(3)

(1)

(2)

(3)

$\begin{array}{ccc}75^{\text {th }} & 50^{\text {th }} & 33^{\text {rd }} \\ \text { Percentile } & \text { Percentile } & \text { Percentile }\end{array}$

$75^{\text {th }}$
Percentile

$50^{\text {th }}$

$33^{\text {rd }}$

Percentile Percentile

0.04

22.40

30.10

$75^{\text {th }}$

$50^{\text {th }}$

Percentile Percentile

$33^{\text {rd }}$

\begin{tabular}{|c|c|c|c|c|c|c|c|c|}
\hline 0.04 & 22.40 & 30.10 & 0.04 & 22.40 & 30.10 & 0.04 & 22.40 & 30.10 \\
\hline-0.62 & -1.30 & -1.96 & -0.62 & -1.30 & -1.96 & -0.77 & -1.55 & -2.30 \\
\hline-0.34 & -0.84 & -1.35 & -0.34 & -0.84 & -1.35 & -0.45 & -1.04 & -1.64 \\
\hline $\mathrm{N} / \mathrm{A}$ & $\mathrm{N} / \mathrm{A}$ & $\mathrm{N} / \mathrm{A}$ & $\mathrm{N} / \mathrm{A}$ & $\mathrm{N} / \mathrm{A}$ & $\mathrm{N} / \mathrm{A}$ & -0.07 & -0.35 & -0.26 \\
\hline 0.96 & 0.88 & 0.82 & 0.95 & 0.86 & 0.77 & 0.94 & 0.84 & 0.74 \\
\hline 0.12 & 0.16 & 0.20 & 0.27 & 0.34 & 0.40 & 0.36 & 0.43 & 0.46 \\
\hline 0.25 & 0.26 & 0.26 & 0.28 & 0.28 & 0.30 & 0.30 & 0.32 & 0.35 \\
\hline 0.24 & 0.23 & 0.23 & 0.24 & 0.24 & 0.23 & 0.24 & 0.24 & 0.26 \\
\hline
\end{tabular}


Table 10. Test-Score-Ceiling Effects on Value-Added Results for School-Level Effects (N=116) - Tobit Versus OLS

\begin{tabular}{|c|c|c|c|c|c|c|c|c|}
\hline & $(1)^{*}$ & (2) & (3) & (4) & (5) & (6) & (7) & (8) \\
\hline $\begin{array}{l}\text { Percentile of Fourth-Grade Test-Score } \\
\text { Distribution Where Ceiling is Set }\end{array}$ & 99.96 & 97 & 95 & 90 & 85 & 75 & 50 & 33 \\
\hline $\begin{array}{l}\text { Skewness of Period-t Score } \\
\text { Distribution }\end{array}$ & 0.17 & -0.02 & -0.07 & -0.25 & -0.37 & -0.64 & -1.31 & -2.00 \\
\hline $\begin{array}{l}\text { Skewness of Period-(t-1) Score } \\
\text { Distribution (not censored) }\end{array}$ & 0.25 & 0.25 & 0.25 & 0.25 & 0.25 & 0.25 & 0.25 & 0.25 \\
\hline $\begin{array}{l}\text { Correlation Between Ceiling-Restricted } \\
\text { Value-Added Estimates estimated by } \\
\text { OLS and Baseline }\end{array}$ & - & 1.00 & 1.00 & 0.99 & 0.98 & 0.95 & 0.86 & 0.78 \\
\hline $\begin{array}{l}\text { Correlation Between Ceiling-Restricted } \\
\text { Value-Added Estimates estimated by } \\
\text { Tobit and Baseline }\end{array}$ & - & 1.00 & 1.00 & 1.00 & 0.99 & 0.99 & 0.95 & 0.90 \\
\hline
\end{tabular}

* Again, column (1) shows results from the no-ceiling baseline. 


\section{References}

Aaronson, Daniel, Lisa Barrow and William Sander 2007. Teachers and Student

Achievement in the Chicago Public High Schools. Journal of Labor Economics 25:95-135.

Arabmazar, Abbas and Peter Schmidt 1981. Further Evidence on the Robustness of the Tobit Estimator to Heteroskedasticity. Journal of Econometrics 17:253-258.

Austin, Peter C. and Lawrence J. Brunner 2003. Type I Error Inflation in the Presence of a Ceiling Effect. The American Statistician 57:97-104

Austin, Peter C. and Jeffrey S. Hoch 2004. Estimating Linear Regression Models in the Presence of a Censored Independent Variable. Statistics in Medicine 23:411-429.

Anderson T.W. and Cheng Hsiao 1981. Estimation of Dynamic Models with Error Components. Journal of the American Statistical Association. 76:598-609.

Betts, Julian, Andrew Zau, and Lorien Rice 2003. Determinants of Student Achievement, New Evidence from San Diego. Public Policy Institute of California.

Brown, Charles and Robert Moffitt 1983. The Effect of Ignoring Heteroscedasticity on Estimates of the Tobit Model. Technical Working Paper no. 27. National Bureau of Economic Research, Cambridge, MA.

Carson, Richard T. and Yixiao Sun 2007. The Tobit Model with a Non-Zero Threshold. Econometrics Journal 10:488-502

Chen, Songhian 2002. Rank Estimation of Transformation Models. Econometrica 70:16831697.

Cullen, Julie Berry and Susanna Loeb 2004. School finance feform in Michigan: Evaluating Proposal A, in J. Yinger (Ed.), Helping Children Left Behind: State Aid and the Pursuit of Educational Equity. Cambridge, MA: MIT Press. pp. 215-250.

Gørgens, Tue and Joel L. Horowitz 1999. Semiparametric Estimation of a Censored Regression Model with an Unknown Transformation of the Dependent Variable. Journal of Econometrics 90:155-191.

Hanushek, Eric, John Kain, Daniel O’Brien and Steven Rivkin 2005. The Market for Teacher Quality. Working Paper no. 11154, National Bureau of Economic Research, Cambridge, MA.

Harris, Douglas and Tim R. Sass 2006. Value-Added Models and the Measurement of Teacher Quality. Unpublished manuscript, Department of Economics, Florida State University, Tallahassee. 
Hurd, Michael 1979. Estimation in Truncated Samples When There is Heteroskedasticity. Journal of Econometrics 11:247-258.

Ingersoll, Gary M., James P. Scamman and Wayne D. Eckerling. 1989. Geographic Mobility and Student Achievement in an Urban Setting. Educational Evaluation and Policy Analysis 11:143-149.

Kane, Thomas and Douglas Staiger. 2002. The Promise and Pitfalls of Using Imprecise School Accountability Measures. Journal of Economic Perspectives 16:91-114.

Koedel, Cory. forthcoming. An Empirical Analysis of Teacher Spillover Effects in Secondary School. Economics of Education Review.

Koedel, Cory and Julian R. Betts. 2007. Re-Examining the Role of Teacher Quality in the Educational Production Function. Working Paper, University of Missouri, Columbia.

-- 2008. How Reliable is Value-Added Modeling? An Extended Analysis of the Rothstein Critique. Working Paper, University of Missouri, Columbia.

Lockwood, J.R., Daniel F. McCaffrey, Laura S. Hamilton, Brian Stecher, Vi-Nhuan Le and Jose Felipe Martinez. 2007. The Sensitivity of Value-Added Teacher Effect Estimates to Different Mathematics Achievement Measures. Journal of Educational Measurement, 44:47-67.

Nye, Barbara, Spyros Konstantopoulos and Larry V. Hedges. 2004. How Large are Teacher Effects? Educational Evaluation and Policy Analysis, 26:237-257.

Podgursky, Michael J. and Mathew G. Springer. 2007. Teacher Performance Pay: A Survey. Journal of Policy Analysis and Management, 26:909-950.

Roberts, Sarah Jane. 1978. Test Floor and Ceiling Effects. ESEA Title I Evaluation and Reporting System. Research report, RMC Research Corporation.

Rockoff, Jonah. 2004. The Impact of Individual Teachers on Student Achievement: Evidence from Panel Data. American Economic Review, Papers and Proceedings.

Rothstein, Jesse. 2008. Teacher Quality in Educational Production: Tracking, Decay, and Student Achievement. Unpublished Manuscript, Princeton University.

Rumberger, Russell W. and Katherine A. Larson. 1998. Student Mobility and the Increased Risk of High School Dropout. American Journal of Education 107:1-35.

Warren, John Robert, State High School Exit Examinations for Graduating Classes Since 1977. Minneapolis, MN: Minnesota Population Center, 2007. Available at http://www.hsee.umn.edu. 